\title{
Retinal microangiopathy and pigment epithelial lesions in subjects with normal, borderline, and decreased oral glucose tolerance
}

\author{
P ALGVERE, S EFENDIC, R LUFT, AND A WAJNGOT \\ From the Departments of Ophthalmology and Endocrinology, Karolinska Hospital, Stockholm, Sweden
}

SUMMARY Retinal fluorescein angiography was performed in 150 subjects: 64 with normal fasting blood glucose and normal oral glucose tolerance test (OGTT), 49 with borderline, and 37 with decreased OGTT. Microaneurysms were noted in only two subjects, both with decreased OGTT. Minute changes in the retinal pigment epithelium (RPE) were seen in 23\% of the 64 normal persons, in $35 \%$ of those with borderline, and $49 \%$ of those with decreased OGTT $(p<0 \cdot 05)$. The impact of glucose intolerance was more pronounced in subjects under the age of 50 years, RPE changes being rare (7\%) in those with normal OGTT but occurring in $32 \%$ of those with borderline or decreased OGTT $(\mathrm{p}<0.01)$. The corresponding figures among subjects aged 50 or more were $55 \%$ and $57 \%$, respectively. We conclude that at least half of the subjects above 50 years show RPE alterations, and that minimal changes in glucose metabolism may precipitate the development of such changes at an earlier age.

The presence of microaneurysms and more advanced signs of diabetic retinopathy at the time of diagnosis of manifest diabetes mellitus has long been recognised and has been reported to occur in $4-15 \%$ of such patients.' Changes compatible with diabetic retinopathy have also been observed in some subjects with decreased oral glucose tolerance (OGTT) only, ${ }^{2}$ as well as in a few with normal OGTT but with renal lesions of the diabetic type. ${ }^{3}$

It has recently been reported that minute changes in the retinal pigment epithelium (RPE), visible both on fluorescein angiograms and colour photographs, occur in about $30 \%$ of normal subjects. ${ }^{4}$ Since RPE has a high metabolic activity and great phagocytic capacity, the question arises whether alterations of RPE precede apparent diabetic vascular changes in the retina. We have therefore investigated the prevalence of RPE changes in younger $(<50$ years of age) and older ( $\geqslant 50$ years) subjects with and without minor impairment of glucose metabolism.

Correspondence to Dr P Algvere, Department of Ophthalmology, Karolinska Hospital, 10401 Stockholm, Sweden.

\section{Material and methods}

\section{SUBJECTS}

The study included 150 subjects (54 females, 96 males), 64 of whom had normal fasting blood glucose and normal OGTT (Table 1). Forty-nine of the subjects had borderline and 37 decreased OGTT. Their age ranged from 23 to 72 years. Those with borderline or decreased OGTT were matched with normal controls for age, sex, and body weight.

All subjects participating in the study were apparently healthy. On the basis of detailed case histories, physical examinations, and a series of laboratory tests, the following diseases could be excluded: anaemia, heart failure, hypertension, liver and kidney disease, malabsorption, and endocrine disorders. In addition in all subjects the insulin response to oral glucose and glucose infusion was measured, and estimates were obtained for insulin secretory capacity and insulin sensitivity. ${ }^{5}$

\section{METHODS}

Oral glucose tolerance test (OGTT). Glucose was given orally in $300 \mathrm{ml}$ of water in a dose of $1.75 \mathrm{~g}$ per $\mathrm{kg}$ body weight, and venous blood samples were 
collected from an indwelling catheter before and at $15,30,45,60,90$, and $120 \mathrm{~min}$. OGTT was assessed according to the criteria in Table 1 , which were adopted from those of Reaven et al. ${ }^{6}$ Glucose in whole blood was measured with glucose oxidase.

The ophthalmological examination included measurements of visual acuity and intraocular pressure, as well as slit-lamp biomicroscopy and ophthalmoscopy.

Fluorescein angiography of the fundi was performed with a Zeiss fundus camera (Oberkocken, West Germany) equipped for angiography (excitation filter: Schott BG 12; barrier filter: Schott GG 14). $5 \mathrm{ml}$ of a $10 \%$ solution of sodium fluorescein was injected into an antecubital vein. A standard 30\% view of the posterior pole of the fundus (centring the macular area) was photographed in both eyes at 1-2 s intervals during the first $30 \mathrm{~s}$ and later at about $15 \mathrm{~s}$ intervals for $3 \mathrm{~min}$. Mydriasis was induced by topical tropicamide (Mydriacyl) and cyclopentolate (Cyclogyl). Fundus photographs in colour were taken from both eyes. The colour slides were projected on a screen and examined under magnification (X 8). The black and white prints of the angiograms $(8 \times 8 \mathrm{~cm})$ were assessed without further magnification by three investigators without knowledge of the patients' glucose tolerance.

\section{Results}

Ophthalmological examination in all subjects disclosed normal visual acuity $(0 \cdot 7-1.0)$ and intraocular pressure and clear ocular media. Retinal vascular changes were limited to slight attenuation of arterioli and pathological arteriovenous crossings in 18 subjects over 50 years of age, equally distributed between the subgroups and controls. No apparent retinal disease was found by ophthalmoscopy except for depigmentation and minor hyperpigmented lesions similar to macular degeneration.

In some subjects, detailed examinations of fluorescein angiograms and fundus colour slides showed changes of the RPE. The prevalence of these alterations - provided they were detected by both methods -is given in Table 2. RPE changes were noted in $23 \%$ of subjects with normal OGTT and in $35 \%$ of those with borderline OGTT. About half of the subjects with decreased OGTT had RPE changes $(\mathrm{p}<0 \cdot 05)$.

These alterations of RPE were characterised on fluorescein angiograms by the following two findings: 'window' defects comprising a variety of alterations ranging from minute dots to multiple or confluent circumscribed areas; and punctate choroidal hyperfluorescence seen as solitary or multiple sharply bordered lesions, some of them looking like drusen
Table 1 Criteria for OGTT

\begin{tabular}{llll}
\hline Groups & \multicolumn{3}{l}{ Venous blood glucose, mmolll } \\
\cline { 2 - 4 } & Fasting & $1 \mathrm{hr}$ & $2 \mathrm{hr}$ \\
\hline Normal & $<5.2$ & $<7.8$ & $<6.4$ \\
Borderline & $<5.2$ & $\geqslant 7.8$ or & $\geqslant 6.4$ \\
Decreased & $<5.2$ & $\geqslant 8.9$ and & $\geqslant 6.7$ \\
\hline
\end{tabular}

Table 2 Prevalence of retinal changes and age of subjects

\begin{tabular}{llll}
\hline & $\begin{array}{l}\text { No. of } \\
\text { subjects }\end{array}$ & $\begin{array}{l}\text { Retinal } \\
\text { changes }\end{array}$ & $\begin{array}{l}\text { Age, years } \\
\text { (mean } \pm \text { SEM) }\end{array}$ \\
\hline A. Normal controls & 64 & $15(23 \%)$ & $43 \pm 1$ \\
B. Borderline OGTT 49 & $17(35 \%)$ & $43 \pm 2$ \\
C. Decreased OGTT 37 & $18(49 \%)^{*}$ & $46 \pm 2$
\end{tabular}

*The difference between groups $A$ and $C$ is significant $(p<0.05)$, that between groups $A$ and $B$ is not.

Table 3 Distribution of 150 subjects with or without retinal changes according to age $(<50$ and $\geqslant 50$ years $)$

\begin{tabular}{lll}
\hline & \multicolumn{2}{l}{ Age of subjects (years) } \\
\cline { 2 - 3 } & $<50$ & $\geqslant 50$ \\
\hline $\begin{array}{lll}\text { Normal controls } \\
\quad \text { No changes }(\mathrm{n}=49)\end{array}$ & 40 & 9 \\
$\begin{array}{l}\text { Retinal changes }(\mathrm{n}=15) \\
\text { Borderline or decreased } \text { OGTT }\end{array}$ & $3(7 \%)$ & $12(57 \%)$ \\
$\quad \begin{array}{l}\text { No changes }(\mathrm{n}=51) \\
\text { Retinal changes }(\mathrm{n}=35)\end{array}$ & 36 & 15 \\
\hline
\end{tabular}

${ }^{*} p<0.01$.

(Figs. 1-4). The RPE changes appeared early during angiography, coinciding with the choroidal filling of dye. They showed little change with time and faded with the choroidal fluorescence. On colour fundus photographs these changes corresponded to depigmented, lightly yellow dots or spots and areas with attenuated RPE.

The prevalence of RPE changes in subjects older than 50 years was not related to OGTT (Table 3 ). On the other hand in the younger groups the prevalence of RPE changes was much higher among those with borderline and decreased OGTT than in normal persons $(p<0.01)$.

Retinal microaneurysms were found in only two subjects, both with decreased OGTT.

\section{Discussion}

The ocular changes encountered in this study were lesions of RPE, and seen as 'window' defects or drusen-like changes on fluorescein angiograms. The RPE lesions, though limited in size and number, were present in $23 \%$ of subjects with a completely 


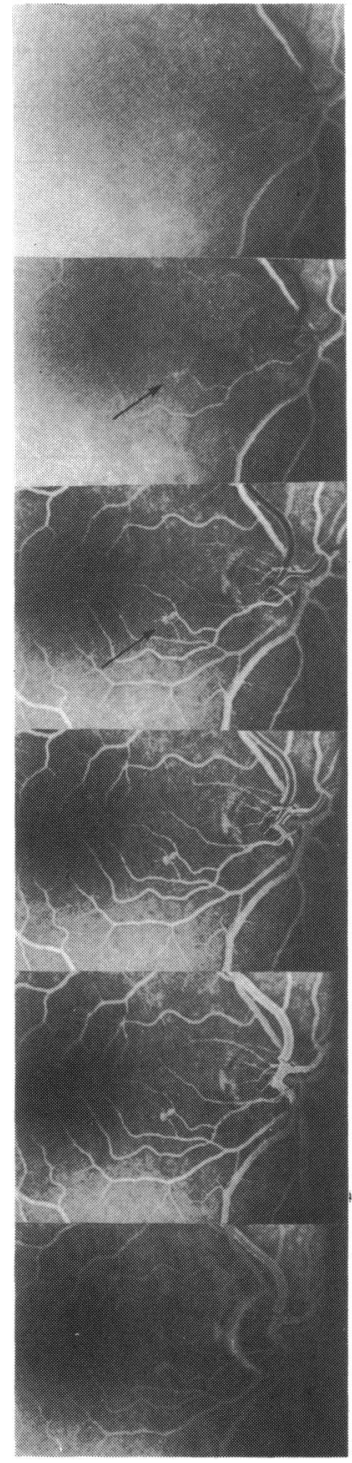

Fig. 1

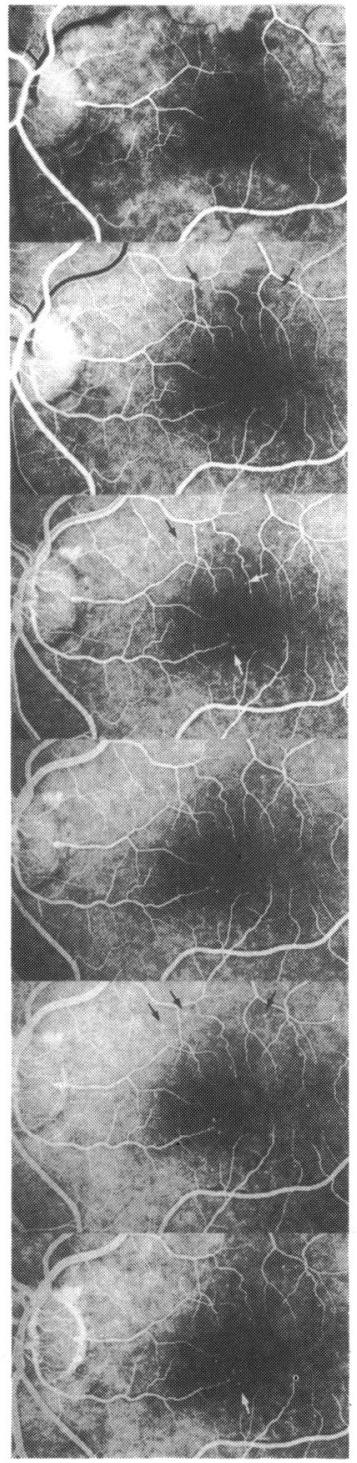

Fig. 2

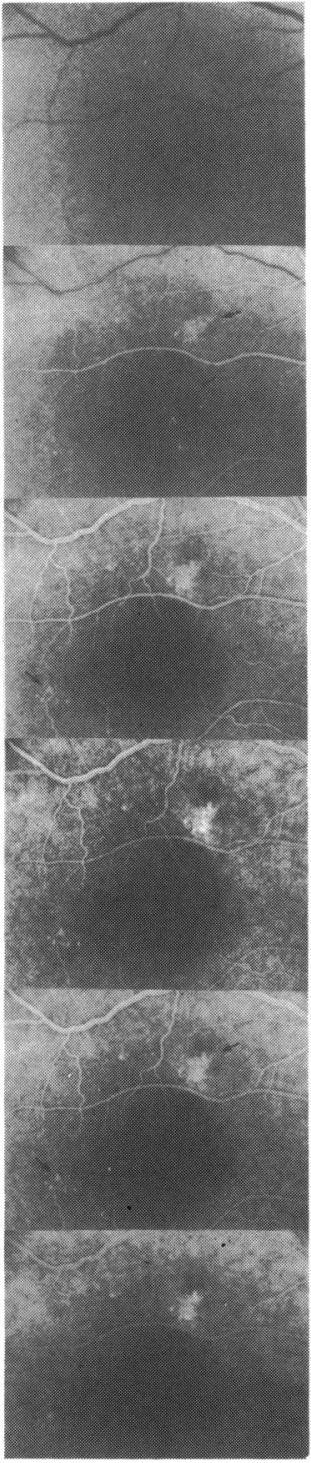

Fig. 3

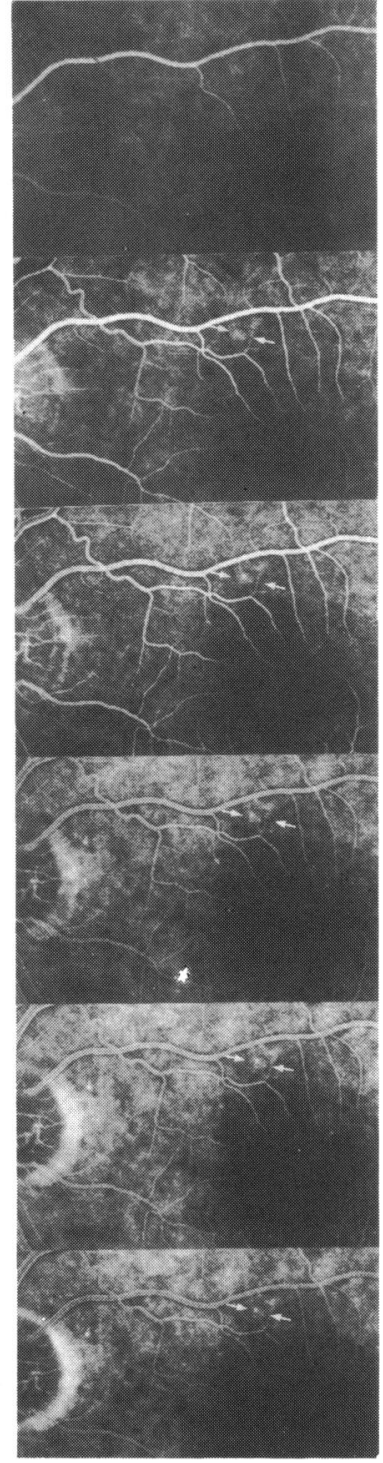

Fig. 4

Figs. 1-4. Fluorescein angiograms in early, arteriovenous, and late phase (about 2 minutes), depicting alterations at the RPE level (arrows). Fig. 1 Hyperfluorescent lesion in papillo-macular area; female aged 54, borderline OGTT.

Fig. 2 Multiple tiny drusen-like changes; female aged 40, borderline OGTT. Fig. 3 Hyperfluorescent spots and a confluent area of attenuated RPE above fovea; male aged 42, decreased OGTT. Fig. 4 Indistinctly bordered hyperfluorescent spots; male aged 47, decreased OGTT.

normal fasting blood glucose and OGTT. This figure underestimates the incidence of these lesions, since only a $30^{\circ}$ view of the fundus was assessed. Recently, subtle morphological elements visible both on fluorescein angiograms and colour photographs were reported in about $30 \%$ of normal subjects when a $45^{\circ}$ view of the fundus was examined. ${ }^{4}$ This figure, when extrapolated to a $30^{\circ}$ view, would correspond to the $23 \%$ in our normal controls.

In subjects with borderline OGTT the incidence of RPE lesions increased to about $35 \%$ and in those with decreased OGTT to $49 \%$. Such a trend towards a higher incidence of retinal lesions parallel with increased disturbances of glucose tolerance is sup- 
ported by observations of such changes in insulindependent diabetics with an onset of the disease prior to the age of 40 years; patients younger than 50 years showed RPE lesions in $53 \%$, and those who were older in $70 \% .^{7}$ In a similar study the incidence of RPE lesions in juvenile diabetics was as high as $80 \%{ }^{8}$

In general, RPE lesions increase with age and probably proceed to senile macular degeneration. ${ }^{9}$ However, electron microscopy has revealed initial RPE changes as early as the age of $30 .{ }^{10}$ In the angiographic 'window' defects the RPE is attenuated, with partial or complete loss of melanin granules, and may be associated with sclerosis of the subjacent choriocapillaries." RPE lesions are often accompanied by drusen, which are regarded as residual products of insufficient phagocytosis by the RPE of photoreceptor outer segments, and recognisèd as basal lamina deposits on Bruch's membrane. ${ }^{12}$ Drusen are often found in diabetics ${ }^{13}$

The scantiness of microaneurysms (found in only two subjects) and the absence of other vascular abnormalities indicate that morphological retinal microangiopathy is rare in conditions prior to manifest diabetes.

In human diabetics increased accumulation of fluorescein into the vitreous, as shown by fluorophotometry, is an early finding which may precede angiographically detectable retinal microangiopathy. ${ }^{14}$ In streptozotocin diabetic rats, also, an enhanced intravitreal concentration of this dye is seen very early during the disease. ${ }^{15}$ The reason for the increased fluorescein accumulation is not clear. Fluorescein is probably eliminated from the vitreous by an active transport mechanism, ${ }^{16}$ and several observations suggest that the RPE may be involved in this process.

Early morphological alterations of the RPE were reported in Streptozotocin-induced ${ }^{17}$ and spontaneously diabetic rats. ${ }^{18}$

The fluorescein extrusion from eyes of normal and diabetic rats can be inhibited by sodium iodate, a substance that results in damage to the RPE. ${ }^{19} 20$

Although conclusive evidence is lacking, impaired function of the RPE may be an early change in experimental diabetes and possibly in human diabetes as well. An interesting question is whether the changes described here constitute an early retinal alteration which goes on to the microangiopathy characteristic of diabetic retinopathy. If so, the RPE changes might possibly be used as an early marker for this type of retinopathy. Only prospective studies can solve this problem. For this reason the subjects with impaired glucose tolerance with or without RPE alterations are being re-examined with regard to glucose tolerance and RPE changes.

This study was supported by a grant from the Swedish Diabetic Association, Stockholm.

\section{References}

1 Soler NG, Fitzgerald MG, Maslins JM, Summers ROC. Retinopathy at diagnosis of diabetes, with special reference to patients under 40 years of age. $\mathrm{Br} \mathrm{Med} J$ 1969; iii: 567-9.

2 Zetterström B, Gjötterberg M. The diagnosis of retinopathy by fluorescein angiography in latent diabetes. Acta Ophthalmol (KGL) 1974; 52: 1-12.

3 Harrower ADB, Clarke BF. Diabetic retinopathy with normal glucose tolerance. BrJ Ophthalmol 1976; 60: 459-62.

4 Nielsen NV. The normal retinal fluorescein angiogram. Acta Ophthalmol (KGL) 1982; 60: 657-70.

5 Efendic S, Wajngot A, Cerasi E, Luft R. Insulin release, insulin sensitivity, and glucose intolerance. Proc Natl Acad Sci USA 1980; 77: 7425-9.

6 Reaven GM, Bernstein R, Davis B, Olefsky JM. Nonketotic diabetes mellitus: insulin deficiency or insulin resistance? $A m \mathrm{~J}$ Med 1976; 60: 80-8.

7 Jerneld B, Algvere P. The prevalence of retinopathy in insulindependent juvenile-onset diabetes mellitus-a fluorescein angiographic study. Acta Ophthalmol (KGL) 1984; 62: 617-30.

8 Palmberg P, Smith M, Waltman S, et al. The natural history of retinopathy in insulin-dependent juvenile-onset diabetes Ophthalmology 1981; 88: 613-8.

9 Sarks SH. Ageing and degeneration in the macular region: a clinico-pathological study. Br J Ophthalmol 1976; 60: 324-41.

10 Hogan MJ. Role of the retinal pigment epithelium in macular disease. Trans Am Acad Ophthalmol Otolaryngol 1972; 76: 64-80.

11 Keno DD, Green R. Retinal pigment epithelial window defect. Arch Ophthalmol 1978; 96: 854-6.

12 Kornzweig AL. Ageing of the retinal pigment epithelium. In: Zinn KM, Marmor MF, eds. The retinal pigment epithelium. Cambridge, Mass: Harvard University Press, 1979: 478-95.

13 Yanoff M, Fine B. Ocular pathology. 2nd ed. Hagerstown, Philadelphia, Harper and Row: 1982: 715.

14 Cunha-Vaz JG, Goldberg MF, Vygantas C, Noth J. Early detection of retinal involvement in diabetes by vitreous fluorophotometry. Ophthalmology 1979; 86: 264-75.

15 Waltman S, Krupin T, Hanish S, Oestrich C, Becker B. Alteration of the blood-retinal barrier in experimental diabetes mellitus. Arch Ophthalmol 1978; 96: 878-9.

16 Blair NP, Zeimer RC, Rusin MM, Cunha-Vaz JG. Outward transport of fluorescein from the vitreous in normal human subjects. Arch Ophthalmol 1983; 101: 1117-21.

17 Grimes PA, Laties AM. Early morphological alteration of the pigment epithelium in streptozotocin-induced diabetes: increased surface area of the basal cell membrane. Exp Eye Res 1980; 30: 631-9.

18 Blair NP, Tso MOM, Dodge JT. Pathologic studies of the bloodretinal barrier in the spontaneously diabetic BB rat. Invest Ophthalmol Vis Sci 1984; 25: 302-11.

19 Anstadt B, Blair NP, Rusin M, Cunha-Vaz JG, Tso MOM. Alteration of the blood-retinal barrier by sodium iodate: kinetic vitreous fluorophotometry and horseradish peroxidase tracer studies. Exp Eye Res 1982; 35: 653-62.

20 Krupin T, Waltman SR, Szewczyk P, et al. Fluorometric studies on the blood-retinal barrier in experimental animals. Arch Ophthalmol 1982; 100: 631-4. 